\title{
GT2020-14973
}

\section{WALL-MODELLED LARGE EDDY SIMULATIONS OF AXIAL TURBINE RIM SEALING}

\author{
Donato M. Palermo, Feng Gao \\ Dario Amirante, John W. Chew \\ Thermo-Fluid Systems UTC \\ Faculty of Engineering and Physical Sciences \\ University of Surrey \\ Guildford, GU2 7XH, United Kingdom
}

\author{
Anna Bru Revert, Paul F. Beard \\ Osney Thermofluids Laboratory \\ Department of Engineering Science \\ University of Oxford \\ Oxford, OX2 0ES, United Kingdom
}

\begin{abstract}
This paper presents WMLES simulations of a chute type turbine rim seal. Configurations with an axisymmetric annulus flow and with nozzle guide vanes fitted (but without rotor blades) are considered. The passive scalar concentration solution and WMLES are validated against available data in the literature for uniform convection and a rotor-stator cavity flow. The WMLES approach is shown to be effective, giving significant improvements over an eddy viscosity turbulence model, in prediction of rim seal effectiveness compared to research rig measurements. WMLES requires considerably less computational time than wall-resolved LES, and has the potential for extension to engine conditions. All WMLES solutions show rotating inertial waves in the chute seal. Good agreement between WMLES and measurements for sealing effectiveness in the configuration without vanes is found. For cases with vanes fitted the WMLES simulation shows less ingestion than the measurements, and possible reasons are discussed.
\end{abstract}

\section{NOMENCLATURE}

Roman symbols

$b \quad$ Disc rim radius

$D \quad$ Artificial viscosity coefficient

$C_{p, a} \quad$ Pressure coefficient $\left(=\frac{\left|P-\langle P\rangle_{\theta}\right|}{0.5 \rho(\Omega r)^{2}}\right)$

$f / \Omega \quad$ Flow modes' frequency normalised by disc frequency

$K^{*} \quad$ Non-dimensional laminar diffusion coefficient

$\dot{m} \quad$ Mass flow rate

$r \quad$ Local radius

$r^{*} \quad$ Non-dimensional radius $(=r / b)$

$r_{m, i} \quad$ Mid radius of the inner seal inlet

$R e_{\phi} \quad$ Rotational Reynolds number $\left(=\rho \Omega b^{2} / \mu\right)$
$R e_{x} \quad$ Annulus axial Reynolds number $\left(=\rho U_{e} b / \mu\right)$

$S_{c} \quad$ Seal clearance

$S_{c t} \quad$ Turbulent Schmidt number $(=0.7)$

$u_{\tau} \quad$ Wall friction velocity $\left(=\sqrt{\tau_{w} / \rho}\right)$

$u^{+} \quad$ Non-dimensional velocity $\left(=u / u_{\tau}\right)$

$v_{\theta, i} \quad$ Inner seal inlet swirl velocity $\left(=0.5 \Omega r_{m, i}\right)$

$U_{e} \quad$ Mean annulus axial velocity

$U_{m} \quad$ Mean velocity through the seal $\left(=\dot{\mathrm{m}} /\left(2 \pi \rho b s_{c}\right)\right)$

$x^{*} \quad$ Non-dimensional axial distance from the stator surface $\left(=\left(x-x_{\text {stator }}\right) /\left(x_{\text {rotor }}-x_{\text {stator }}\right)\right)$

$y^{+} \quad$ Non-dimensional wall distance $\left(=\rho u_{\tau} \Delta y / \mu\right)$

\section{Greek symbols}

$\chi_{a} \quad$ Species concentration at main annulus inlet

$\chi_{i} \quad$ Species concentration at coolant inlet

$\Delta \quad$ Difference

$\varepsilon \quad$ Sealing effectiveness $\left(=\left(\chi-\chi_{a}\right) /\left(\chi_{i}-\chi_{a}\right)\right)$

$\kappa \quad$ von Kármán constant $(=0.41)$

$\mu \quad$ Dynamic viscosity

$\mu_{w} \quad$ Effective dynamic viscosity from wall function

$v \quad$ Kinematic viscosity

$\omega_{s} / \Omega$ Speed of flow modes normalised with the rotor speed

$\Omega \quad$ Disc Angular speed or disc frequency

$\rho \quad$ Density

$\tau_{w} \quad$ Wall shear stress estimated with wall function $\left(=\left(\mu_{w}+\mu\right) u / \Delta y\right)$

$\theta$ Angle or quantity evaluated in the tangential direction

Subscripts

$x \quad$ axial component

$0 \quad$ Initial condition. 


\begin{tabular}{ll}
\multicolumn{2}{l}{ Abbreviations } \\
CFD & Computational fluid dynamics \\
LES & Large eddy simulation \\
ILES & Implicit LES \\
RANS & Reynolds-averaged Navier-Stokes \\
SGS & Subgird scale \\
URANS & Unsteady RANS
\end{tabular}

\section{INTRODUCTION}

Estimation of hot gas ingestion through turbine rim seals is important for gas turbine design and optimisation, but has proved challenging for computational fluid dynamics (CFD). Several studies have found that steady and unsteady Reynoldsaveraged Navier-Stokes (RANS) models under predict ingestion compared to measurements. Large-eddy simulations (LES) have shown improvements on steady and unsteady RANS predictions but have still underestimated measurements [1].

Figure 1 gives an illustration of major flow mechanisms in turbine rim sealing [2]. These include the disc pumping effect, pressure asymmetry induced by the annulus vanes and blades, and inertial waves. In the presence of inertial waves many RANS and unsteady RANS (URANS) models and empirical correlations fail to predict the sealing effectiveness [3].

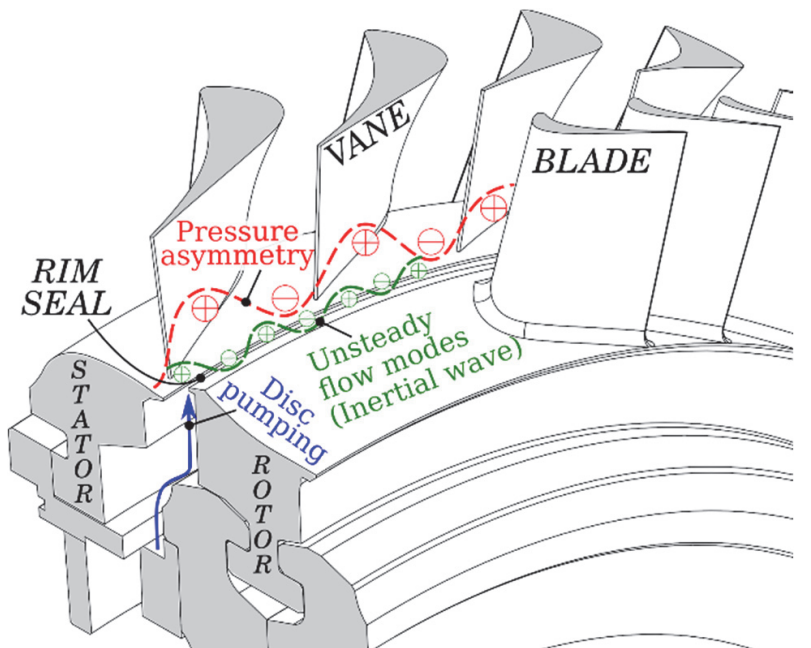

FIGURE 1: MAJOR FLOW MECHANISMS IN TURBINE RIM SEALING [2].

Recently, an explicit LES method employing a linear reconstruction of the flux at the cell interface was developed and applied to a rotor-stator cavity flow at a modest Reynolds number [4], showing promising agreement with data for the prediction of the main engineering parameters. Gao et al. [5] applied this LES method to simulate a chute type turbine rim sealing flow in an axial turbine rig comparing with measurements by Beard et al. [6]. The wall-resolved LES model showed considerable improvement on RANS and URANS models in terms of the pressure coefficient at the seal clearance. The LES model also captured the low frequency unsteady flow modes found in the experiment. Analysing Gao et al.'s LES data [5,7], Chew et al. [3] associated these unsteady flow modes with inertial waves. This has been later confirmed by a further LES study by Gao et al. [2]. Gao et al.'s wallresolved LES study, though having shown promising agreement with the experiment, was limited to simple configurations without blades and vanes due to the high computational requirements of resolving near-wall turbulent flow motions.

Almendral-Fernandez et al. [8] reported a hybrid URANS/ILES (implicit LES) study of the rim sealing problem on a more complex engine representative geometry with blades and vanes. For the internal air system flow ILES [4] was used, whereas the main annulus gas path flow was calculated using URANS with the Spalart-Allmaras turbulence model [9]. Cavity sealing effectiveness was quantified in terms of cavity temperatures and compared with thermocouple data available from experiments. Better alignment with experimental data was obtained at the outer part of the cavity as opposed to the inner part of cavity where only small improvements (about 6\%) were found compared to URANS calculations. This work indicates that with hybrid methods simulation of realistic engine conditions is possible with today's computational capability.

Horwood et al. [10] used URANS models on a radial seal in an axial turbine rig. They performed a sensitivity study, varying sealing flow rate, sector size and disc rotational speed. The inherent large-scale unsteady flow structures identified were found sensitive to sealing flow rates whereas sector size and rotational rate had weaker effects on these flow structures. Only a qualitative agreement of sealing effectiveness data was obtained with mismatches between CFD and experiment attributed to deficiencies of turbulence modelling. Using a similar CFD methodology Horwood et al. [11] also assessed a chute seal fitted in an axial turbine. Overall agreement between the CFD and the measurement was obtained at several operating conditions. This is particularly interesting as other studies of chute seals have found discrepancies between CFD and experiment, and differences between URANS and LES predictions [1].

Pogorelov et al. [12] performed a full annulus LES simulation, where the near wall flow was not fully resolved. The model included both blades and vanes with an axial rim seal. Overall, for the single operating condition reported, a good match of calculated and measured sealing effectiveness was obtained. In addition, Pogorelov et al.'s results confirm experimental evidence that use of a double lip seal geometry dramatically improves sealing and reduces the unsteadiness in the seal compared to the single lip geometry. This effect is consistent with interpretation of the rotating rim seal flow modes as inertial waves as described by Chew et al. [3] and Gao et al. [2].

Through the above review, it is clear that use of wallresolved LES is severely restricted by high computing requirements associated with the needs of fine meshes and small timesteps. Therefore, at higher Reynolds numbers representative of engine conditions, simulation time can be greatly reduced by relaxing the minimum grid element size at 
the wall and thus also allowing larger timesteps. In this regard wall-modelled LES (WMLES) offers an attractive alternative to wall-resolved LES, provided it can be shown adequately accurate. A number of studies [13-15] have indicated that WMLES is a viable approach for rotating flows, despite its limitations in calculating the near wall flow. Also, the capability of URANS in predicting chute turbine rim sealing flows shows mixed conclusions.

In the present study, WMLES is adopted to evaluate the sealing effectiveness of a chute turbine rim seal at engine representative test conditions, in comparison with experimental measurements and URANS solutions. In Sections 2 and 3 implementation and validation of a passive scalar transport equation and WMLES are reported, comparing with available analytical and experimental data. Section 4 reports evaluation of the method for a chute turbine rim seal. Flow and ingestion predictions are compared with URANS and experimental results. The main conclusions are summarised in section 5 .

\section{NUMERICAL METHOD}

A development version of Hydra, a Rolls-Royce plc proprietary CFD code [4], is used here. It is based on a cellvertex, unstructured finite volume method. For URANS simulations, an implicit dual time stepping scheme was used. For LES and WMLES an explicit three-stage Runge-Kutta scheme was used for the time advancement. The time step is constrained by the Courant-Friedrichs-Lewy (CFL) condition.

Figure 2 depicts unstructured meshes in Hydra for the standard code and Amirante and Hills' modified code [4]. The standard second order flux calculation on the edge connecting nodes $i, j$ is based on the following edge flux splitting scheme of Roe [16].

$H_{i j}=\frac{1}{2}\left(H\left(Q_{j}\right)+H\left(Q_{i}\right)\right)-\frac{1}{2} D\left|A_{i j}\right|\left(L_{j}^{p}(Q)-L_{i}^{p}(Q)\right)$

where $Q$ is the vector of the primitive variables and $A_{i j}$ is the Jacobian of the inviscid flux. $L^{p}$ is the pseudo-Laplacian operator and $D$ is the artificial viscosity coefficient to control the amount of numerical dissipation.

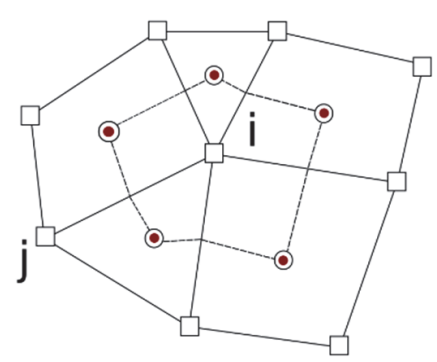

(a)

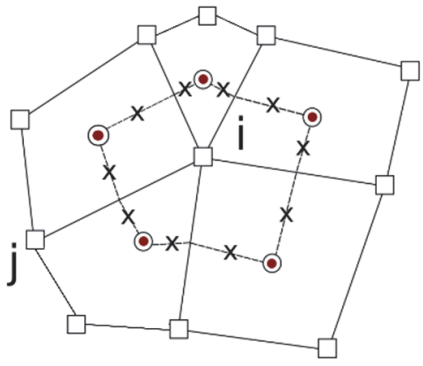

(b)
FIGURE 2: BI-DIMENSIONAL GEOMETRY REPRESENTATION OF AN UNSTRUCTURED GRID USED BY (a) THE STANDARD HYDRA, AND (b) THE MODIFIED VERSION OF HYDRA [4]

Note the smoothing term on the right-hand side represents numerical smoothing which stabilises the solution. The artificial viscosity coefficient $D$ should be chosen close to the minimum possible for stability as otherwise it may lead to excessive dissipation of turbulent eddies within the fluctuating flow field.

Flux reconstruction in the standard method follows the dual median approach in which edge flux is computed on a single Gauss integration point located halfway between the two nodes. In the modified version of Hydra, an additional Gaussian point is considered using a modified second-order MUSCL scheme based on the approximate Riemann solver of Roe [16], and a Green-Gauss method for gradient evaluation [17]. Therefore, the number of flux integration points for each edge is doubled, offering a more accurate flux computation. In particular, with the additional Gaussian integration point, an exact integration of a linear curve is achieved eliminating the first order error in the standard flux computation.

A passive scalar solution has been introduced in order to quantify rim seal ingestion. The non-dimensional scalar transport equation is as follows:

$$
\frac{\partial\left(\rho^{*} \chi^{*}\right)}{\partial t^{*}}+\frac{\partial}{\partial x_{i}^{*}}\left(\rho^{*} u_{i}^{*} \chi^{*}\right)=\frac{\partial}{\partial x_{i}^{*}}\left(\rho^{*}\left(K^{*}+\frac{v_{t}^{*}}{S c_{t}}\right) \frac{\partial \chi^{*}}{\partial x_{i}^{*}}\right)
$$

where $K^{*}$ is the non-dimensional laminar diffusion coefficient, $S_{c t}=0.7$ is the turbulent Schmidt number, and $\chi^{*}$ is the dimensionless, species concentration. This is implemented in Hydra as an additional partial differential equation.

Implementation of the wall function for WMLES is depicted in Fig. 3. The concept of the wall function is to construct an effective viscosity that models the near-wall flow behaviour and contributes to the viscous flux calculation of the near wall grid cell, for example, the cell centred at node N2. The effective viscosity $\mu_{w}$ on the wall, for example, at N1, is formulated such that it can approximate the wall shear stress $\tau_{w}$ with the instantaneous velocity $u$ relative to the wall on grid node $\mathrm{N} 2$ and the corresponding wall distance $\Delta y$, as given in Eq. (3). Note that $\tau_{w}$ and $u$ are assumed to be in-phase. As given in Eq. (4) the wall shear stress is also associated with the wall friction velocity $u_{\tau}$, using the flow variables at node N2. This can be obtained by iteratively solving the formula for the law of the wall by Spalding [18] in Eq. (5). In this algebraic wall function the law of the wall is assumed valid locally and instantaneously [19]. The acquired effective viscosity is applied in calculation of the viscous flux at the cell interface F1 in the present study, where on the other side (F2) the viscous flux is estimated using the subgrid-scale (SGS) viscosity $\mu_{\mathrm{SGS}}$.

$$
\tau_{w}=\left(\mu_{w}+\mu\right) \frac{u}{\Delta y}
$$

where $\mu$ is the molecular viscosity.

$$
\tau_{w}=\rho u_{\tau}^{2}
$$

$$
y^{+}=u^{+}+\frac{1}{E}\left(e^{\kappa u^{+}}-1-\kappa u^{+}-\frac{\left(\kappa u^{+}\right)^{2}}{2 !}-\frac{\left(\kappa u^{+}\right)^{3}}{3 !}\right)
$$

where $y^{+}=\rho u_{\tau} \Delta y / \mu$ is the non-dimensional wall distance, $u^{+}=u / u_{\tau}, \kappa=0.41$ the von Kármán constant, and $E=8.8$. 


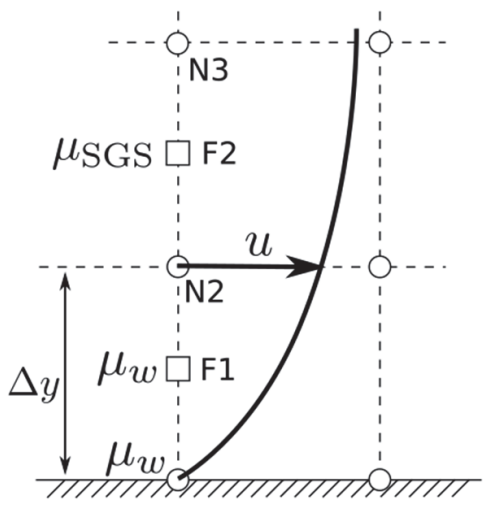

N1

FIGURE 3: WMLES CONCEPT FOR A CELL-VERTEX SCHEME SOLVER. 'N' DENOTES GRID NODE. 'F' INDICATES THE CELL FACE BETWEEN TWO GRID NODES WHERE THE VISCOUS FLUX CONTRIBUTION IS EVALUATED.

\section{CFD VALIDATION}

\subsection{Scalar Transport in a Uniform Flow}

To validate the passive scalar equation comparisons are made with available analytical and URANS solutions following Boudet [20].

A flow domain is a rectangular prism extending over $\left(L_{x}=\right.$ $0.01 \mathrm{~m}) \times\left(L_{y}=0.035 \mathrm{~m}\right) \times\left(L_{z}=0.022 \mathrm{~m}\right)$ is considered. This is discretised using a Cartesian grid with $32 \times 88 \times 77=$ 216832 nodes uniformly distributed in each direction. For all computations the flow field was initialised as follows,

$$
\left\{\begin{array}{l}
\rho_{0}=1.226 \mathrm{~kg} \cdot \mathrm{m}^{-3} \\
u_{0}=0 \mathrm{~m} \cdot \mathrm{s}^{-1} \\
v_{0}=100 \mathrm{~m} \cdot \mathrm{s}^{-1} \\
w_{0}=0 \mathrm{~m} \cdot \mathrm{s}^{-1} \\
p_{0}=101300 \mathrm{~Pa} \\
\chi_{0}=0.01 \mathrm{e}^{-\left(\frac{(y-0.0175)^{2}}{2 \times 10^{-5}}\right)}
\end{array}\right.
$$

In addition, for URANS computation the Spalart-Allmaras turbulence model was considered with the turbulent eddy viscosity $v_{t}=1.76165 \times 10^{-4} \mathrm{~m}^{2} \cdot \mathrm{s}^{-1}$.

Consider the $1 \mathrm{D}$ diffusion equation:

$$
\frac{\partial \chi}{\partial t}=K \frac{\partial^{2} \chi}{\partial x^{2}}
$$

an analytical solution for uniform convection exists and can be written as follow

$$
\chi(x, t)=\frac{\chi_{0}}{\sqrt{4 \pi K t}} e^{-\left(\frac{x^{2}}{4 K t}\right)}
$$

After convecting at a velocity $\vec{u}$ for a time $t$, the value of $\chi$ at the location $\vec{x}$ corresponds to the initial passive scalar distribution $\chi$ at $\vec{x}-t \vec{u}$.

Unsteady computations were carried out, using inviscid wall boundary conditions on the sides $\left(x_{\min }, x_{\max }, z_{\min }\right.$ and $\left.z_{\max }\right)$, and a periodic condition between $y_{\min }$ and $y_{\max }$. An ILES was conducted using an explicit three-step Runge-Kutta scheme with $\mathrm{CFL}=1$, and results are compared with analytical solutions and URANS data obtained by Boudet [20].

Computed distributions of passive scalar at times $t_{2}=t_{0}+$ $4.64 L_{y} / v_{0}$ and $t_{3}=t_{0}+5.10 L_{y} / v_{0}$, are presented in Fig. 4, together with the corresponding analytical solutions. The initial distribution is also shown for reference. Note that the scalar has already been convected about 5 times through the periodic boundary at $t_{3}$.

The prediction is in good agreement with the analytical solution, in terms of the peak location of the passive scalar. The URANS is more diffusive than the ILES. The ILES solutions show better agreement with the analytical solutions, compared to URANS.

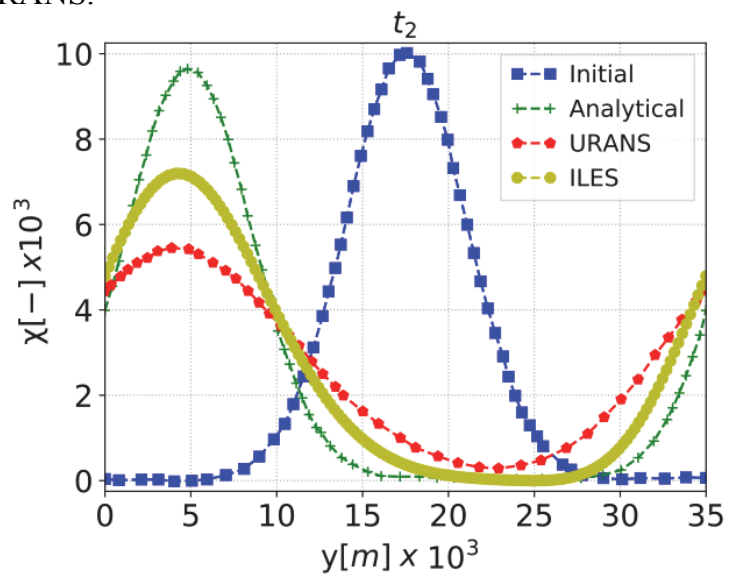

(a)

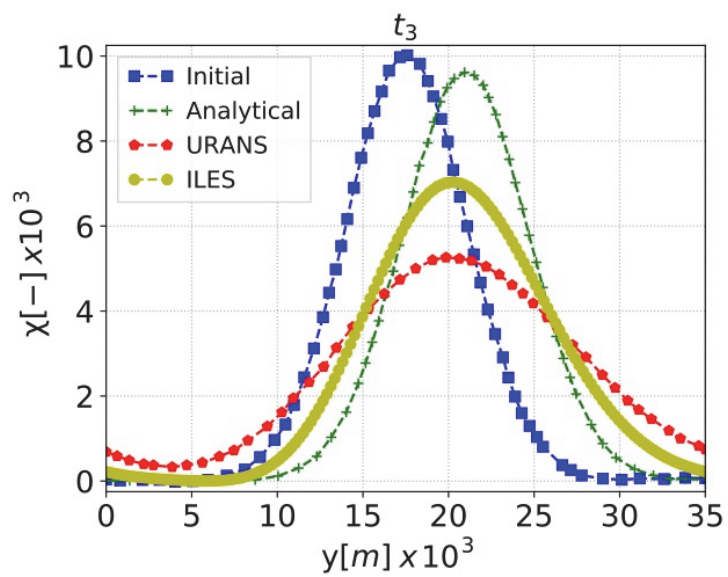

(b)

FIGURE 4: RESULTS FOR SCALAR TRANSPORT IN UNIFORM CONVECTION AT (a) $t_{2}=t_{0}+4.64 \frac{L_{y}}{v_{0}} \operatorname{AND}$ (b) $t_{3}=t_{0}+5.10 \frac{L_{y}}{v_{0}}$. 


\subsection{Rotor-Stator Disc Cavity Flow}

The WMLES is validated in this section for a rotor-stator disc cavity flow [21], as depicted in Fig. 5. The radii of the shaft and the shroud are $a$ and $b$, respectively. The distance between the stator disc and the rotor disc is $h$. The nondimensional parameters such as the aspect ratio $G$ and the curvature parameter $R_{m}$ are given in Tab. 1. The shaft and rotor spin at a constant angular speed $\Omega$, while the shroud and stator are stationary. A low Mach number $(M a)$ condition is considered here, as shown by the operating conditions in Tab. 1.

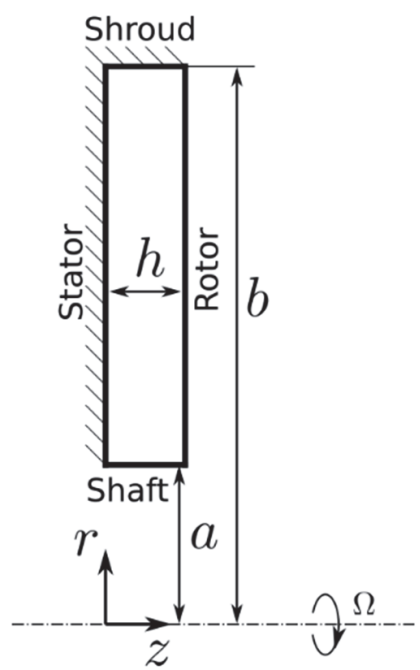

FIGURE 5: ROTOR-STATOR GEOMETRY [21]

TABLE 1: OPERATING CONDITIONS AND ROTOR-STATOR CAVITY TEST CASE.

\begin{tabular}{ccc}
\hline Symbol & Definition & Value \\
\hline$G$ & $(b-a) / h$ & 5 \\
$R_{m}$ & $(b+a) /(b-a)$ & 1.8 \\
$M a$ & $\Omega b / \sqrt{\gamma R T}$ & 0.2 \\
$R e_{\phi}$ & $\Omega b^{2} / \nu$ & $4 \times 10^{5}$ \\
\hline
\end{tabular}

All the simulations reported in this paragraph were initialised with a steady-state LES solution from Amirante and Hills [4]. This solution shows radially inwards turbulent flow on the stator feeding the rotor boundary layer, which is laminar at lower radii and turbulent in the outer part of the cavity.

Time- and circumferentially-averaged swirl velocity and tangential Reynolds normal stress profiles at $r^{*}=(r-$ $a) /(b-a)=0.7$ are shown in Figs. 6 and 7. The RANS, LES and WMLES results are compared to the experimental data. Results were also examined at radial locations in the inner cavity $\left(r^{*}=0.3\right)$ and mid-cavity $\left(r^{*}=0.5\right)$ but are not included here as they give similar conclusions. The results show the sensitivity to numerical dissipation, grid resolution at the wall, and turbulence modelling.

The WMLES solutions show very good agreement with the measurements. The fine mesh WMLES $\left(y^{+}=1\right)$ results in Fig. 6 agree with the wall-resolved LES. When the grid is coarsened at the wall $\left(y^{+}=10\right)$ the WMLES still shows good agreement with the wall resolved LES and the experimental data, in terms of the swirl ratio $u_{\theta} /(\Omega r)$. The WMLES with $y^{+}=10$ underestimates the tangential velocity fluctuations $u_{\theta, \mathrm{rms}}^{\prime} /(\Omega r)$. A slight overestimate of the mean swirl ratio is observed as the artificial viscosity coefficient $D$ is increased. The RANS model (without a transition model) has overpredicted the mean swirl ratio which might be due to the absence of relaminarisation and transition mechanisms.

Performance of the WMLES was also assessed at a higher $R e_{\phi}$ of $4.4 \times 10^{6}$ closer to the conditions considered in the present rim sealing study. Reasonable agreement with Daily and Nece's measurements [22] was found with similar nearwall mesh resolution to that used here.

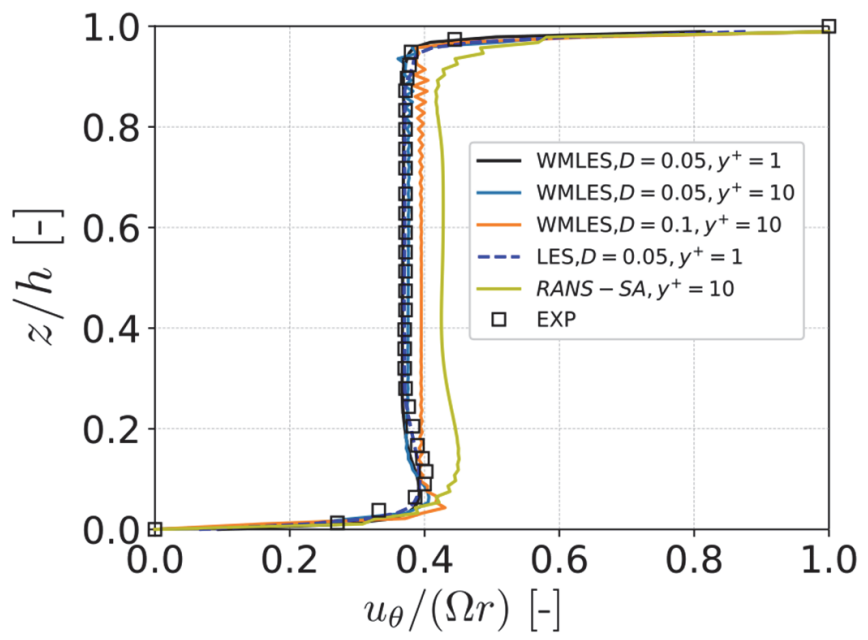

FIGURE 6: TIME- AND CIRCUMFERENTIALLY-AVERAGED SWIRL RATIO $u_{\theta} /(\Omega r)$ AT $r^{*}=0.7$ FOR THE ROTOR-STATOR CAVITY FLOW.

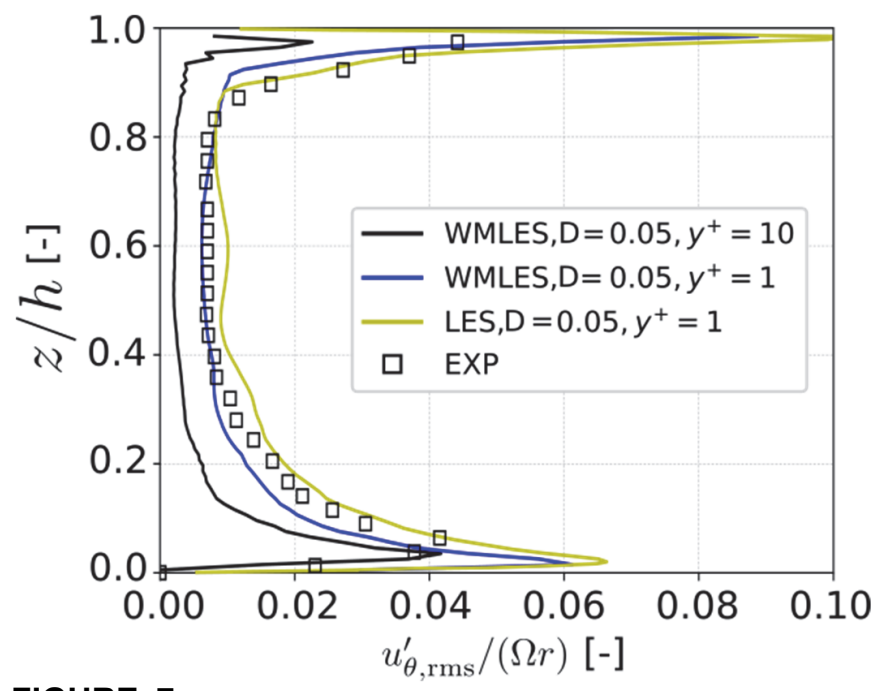

FIGURE 7: TIME- AND CIRCUMFERENTIALLY-AVERAGED TANGENTIAL VELOCITY FLUCTUATIONS $u_{\theta, \mathrm{rms}}^{\prime} /(\Omega r)$ AT $r^{*}=0.7$ FOR THE ROTOR-STATOR CAVITY FLOW 


\section{TURBINE RIM SEALING}

The experiment with a chute rim seal, as described by Beard et al. [6] and Bru Revert et al. [23], is considered here. Results for configurations with and without nozzle guide vanes, but without rotating blades, are presented. Sealing effectiveness predictions for these configurations using URANS models were reported in Ref. [24]. In this paper, the present WMLES and previous URANS solutions are compared with the sealing effectiveness measurements. Readers are referred to Ref. [23] for further details of the experimental work.

\subsection{Model Description and Convergence}

The geometry of the rim seal cavity and a representation of the CFD mesh are shown in Figs. 8 and 9. These show a disc cavity and a chute seal with $1 \mathrm{~mm}$ clearance as in previous work [24]. Vanes are fitted upstream of the rim seal in the mesh shown. The vane exit flow angle is about $66^{\circ}$. The CFD domain is a circumferentially periodic $10^{\circ}$ sector, including one of the 36 vanes in the full annulus. A similar domain was used for the configuration without vanes. For the vaneless configuration an additional $20^{\circ}$ sector test case is considered to assess the effect of the sector size.

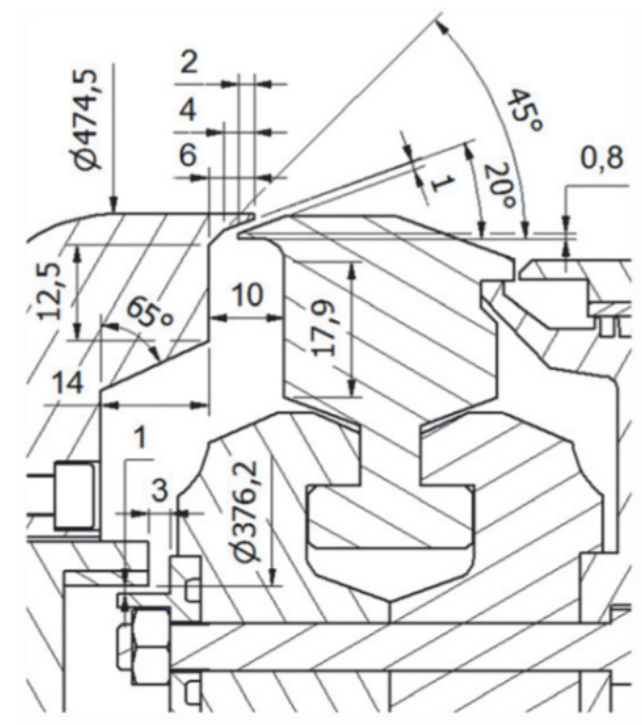

FIGURE 8: GEOMETRY OF THE RIM SEAL CAVITY [6].

The mesh used here is similar to that in the URANS study [24]. In this work, hexahedral meshes (generated with ICEMCFD [25]) were set up to meet the grid requirements in Tab. 2. The coarse mesh normal to the wall overcomes the tight restrictions of the time-step for the explicit temporal scheme, as discussed above. For all WMLES results presented ILES is used. Amirante and Hills [4] and Onori et al. [26] have previously showed with their simulations that far from the wall the SGS dissipation has negligible effects compared to the total dissipation. Close to the wall, viscous dissipation is modelled using the wall function up to the first grid off the wall.

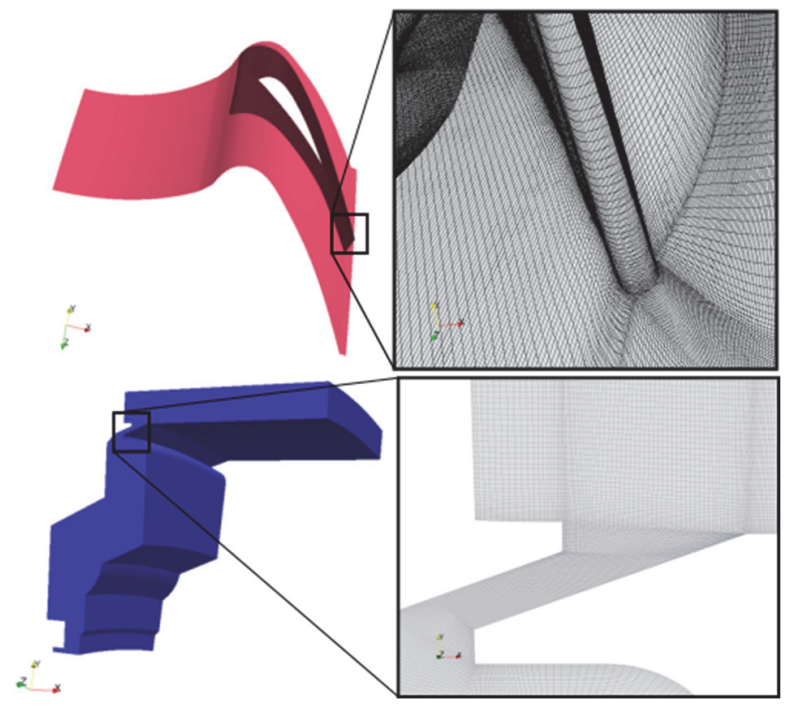

FIGURE 9: EXAMPLE OF CFD MESH FOR THE GEOMETRY WITH VANES.

TABLE 2: MESH SPACING FOR WMLES.

\begin{tabular}{cccc}
\hline & $\boldsymbol{\Delta} \boldsymbol{x}^{+}$ & $\boldsymbol{\Delta}(\boldsymbol{r} \boldsymbol{\theta})^{+}$ & $\boldsymbol{\Delta} \boldsymbol{r}^{+}$ \\
\hline Seal & $<40$ & $<80$ & $<18$ \\
Cavity & $<21$ & $<43$ & $<40$ \\
\hline
\end{tabular}

No-slip wall boundary conditions have been specified on all rotating and stationary solid surfaces, as appropriate. Mass flow rates have been specified at the main annulus and inner seal inlets, with flow normal to the boundaries unless otherwise stated. For both vaneless and vaned configurations at $9000 \mathrm{rpm}$, additional test cases with inner seal inlet swirl are considered to evaluate its effects. In these cases the inner seal inlet swirl velocity is set to half the rotor tangential velocity at the midradius of the inlet plane. At the annulus outlet, a partially nonreflective boundary condition is applied following the approach of Poinsot and Lele [27] to avoid spurious reflections of acoustic waves from the outlet boundary. The passive scalar concentration was set to unity at the inner seal inlet $\left(\chi_{i}=1\right)$ and zero at the annulus inlet $\left(\chi_{a}=0\right)$. Therefore, the calculated species concentration value corresponds directly to the sealing effectiveness $\quad\left(\varepsilon=\left(\chi-\chi_{a}\right) /\left(\chi_{i}-\chi_{a}\right)\right)$. The vaneless configuration considers a weak annulus flow, while the vaned configuration considers three rotor speeds for a turbine designed annulus flow rate. These conditions are summarised in Tab. 3.

For the $9000 \mathrm{rpm}$ condition, the time step is $7.41 \times 10^{-7} \mathrm{~s}$, corresponding to the time for the rotor to rotate 0.04 degree. Convergence of the flow solution to statistically steady state is typically achieved after $\sim 6$ rotor revolutions. Figure 10 shows the normalised pressure signal and the accumulative mean pressure results at 5 locations (as given in the inset) for the $9000 \mathrm{rpm}$ test case with vanes. The statistics are collected after 6 revolutions and the statistics converge within $\sim 4$ revolution. 
All the simulations were initialised from a converged RANS solution. Convergence of the passive scalar concentration can take much longer. For URANS calculations [24], up to 80 revolutions were found necessary to achieve convergence to statistically steady state. This is discussed further below, where the sealing effectiveness results are presented.

TABLE 3: OPERATING CONDITIONS FOR THE TWO CONFIGURATIONS

\begin{tabular}{ccc}
\hline & with vanes & without vanes \\
\hline$U_{e}$ & $115 \mathrm{~m} / \mathrm{s}$ & $11.5 \mathrm{~m} / \mathrm{s}$ \\
$U_{m} / U_{e}$ & $0.16-0.17$ & 0.78 \\
$U_{m} / \Omega b$ & $0.08-0.20$ & 0.04 \\
$R e_{x}$ & $1.87 \times 10^{6}$ & $1.87 \times 10^{5}$ \\
Rotor speed (rpm) & $6000,7850,9000$ & 9000 \\
$R e_{\phi}$ & $1.61-3.63 \times 10^{6}$ & $3 \times 10^{6}$ \\
\hline
\end{tabular}

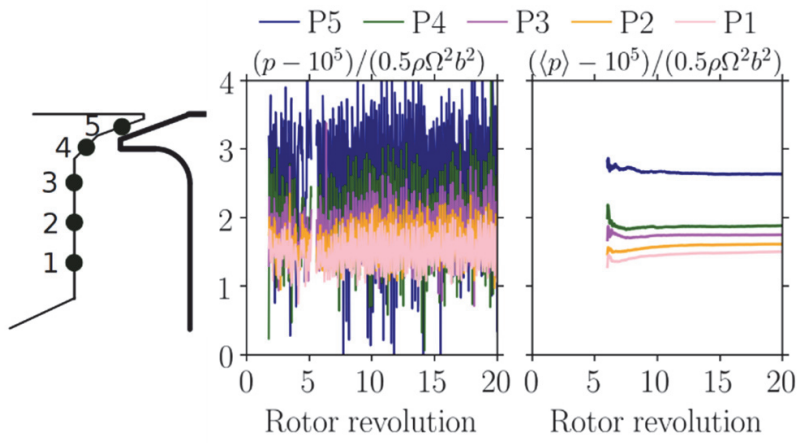

FIGURE 10: CONVERGENCE OF THE PRESSURE SIGNAL. VANED CONFIGURATION, 9000 RPM.

The velocity spectra from two WMLES simulations with and without vanes are plotted in Fig. 11, with the probe location given in the inset. Both cases have shown spectra with $-5 / 3$ slopes, indicating the mesh can resolve the inertial subrange as required for LES.
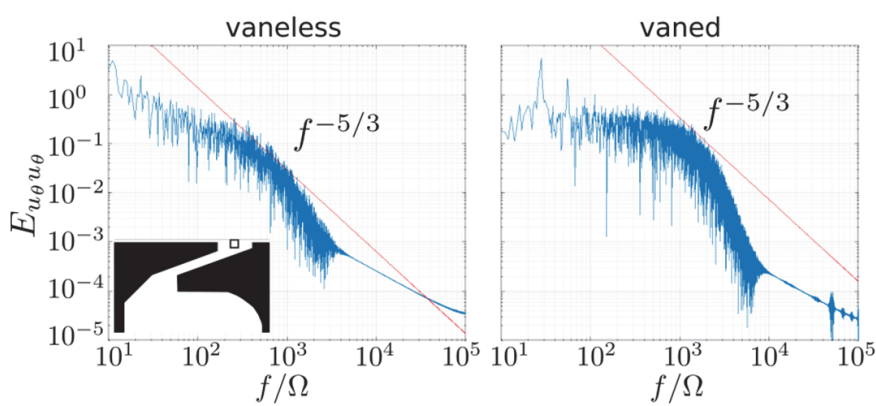

FIGURE 11: TANGENTIAL VELOCITY SPECTRA FROM WMLES. THE PROBE LOCATION IS GIVEN IN THE INSET.

The computational costs are compared for the vaneless test cases at 9000rpm with $280 \mathrm{CPU}$ cores. The wall resolved URANS requires 9.4 hours wall time to finish 1 rotor revolution, whereas the WMLES uses 19.5 hours wall time to complete one rotor revolution. Wall resolved LES is not possible for this speed, but that at a lower speed (7000rpm) [5] has used more than 6 days wall time for one rotor revolution.

\subsection{Flow Characteristics}

The flow structure predicted by the WMLES is qualitatively similar to that found in previous LES and URANS studies [5,24]. An approximate forced vortex at about half disc speed develops in the disc cavity with boundary layer inflow and outflow on the stationary and rotating discs respectively. Figure 12 shows instantaneous contours of sealing effectiveness from URANS and WMLES for the configuration with vanes at $9000 \mathrm{rpm}$. Both solutions show main annulus flow ingestion in the outer part of the chute seal, but penetration of ingestion into the cavity is only apparent for the WMLES. It is also apparent that the WMLES does capture some large scale turbulence.

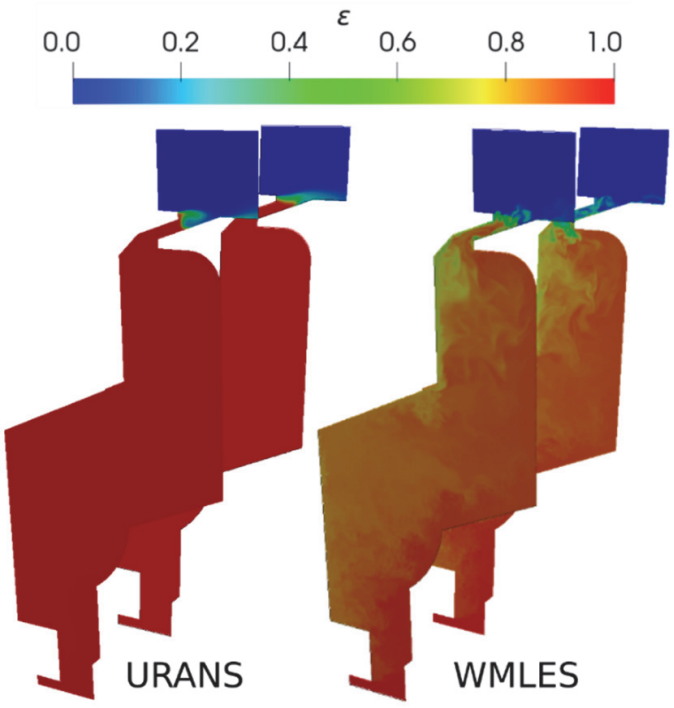

FIGURE 12: INSTANTANEOUS SEALING EFFECTIVENESS CONTOURS FOR VANED CONFIGURATION AT 9000 RPM.

As in previous URANS and LES studies, the present WMLES shows rotating flow modes/inertial waves developing in the chute seal region. A Fourier analysis of unsteady pressures on the stator was undertaken to investigate their frequency content.

Tables 4 and 5 summarise the dominant frequencies and rotational speeds of the flow structures identified, for the vaneless and vaned configurations respectively. For the vaneless configurations, the secondary flow structures show little sensitivity to inlet swirl or sector size. All three cases capture flow structures with 36 or 72 lobes in the full $360^{\circ}$ annulus, rotating at similar speeds. The flow structures with 36 lobes in the full $360^{\circ}$ annulus are shown by the density contours in Fig. 13, these correspond to one lobe in the $10^{\circ}$ sector and two lobes in the $20^{\circ}$ sector. For the $20^{\circ}$ sector test case, reduced peak amplitudes are shown in the frequency spectra plots. The results with inlet swirl show the highest peak amplitudes. This may be linked to stronger ingestion in this case, as will be discussed later. 


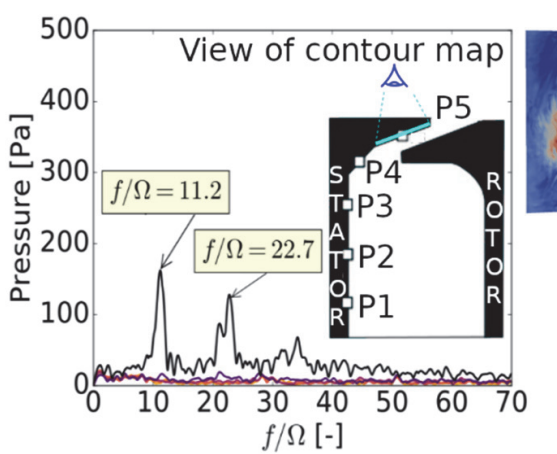

(a) $10^{\circ} \mathrm{SECTOR}$

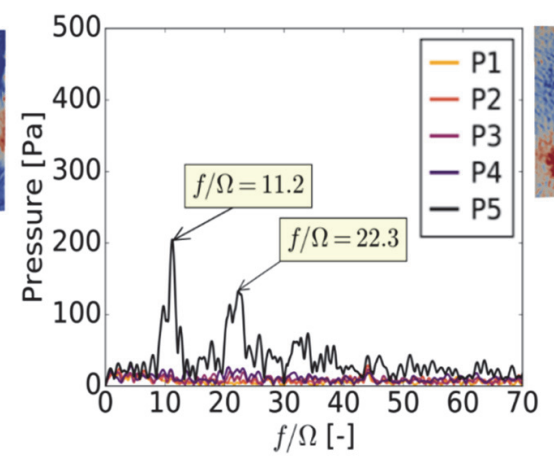

(b) $10^{\circ} \mathrm{SECTOR}, v_{\theta, i}=0.5 \Omega r_{m, i}$

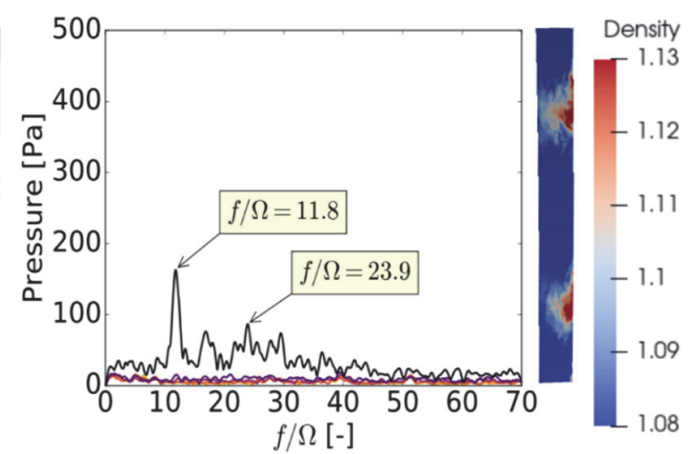

(c) $20^{\circ} \mathrm{SECTOR}$

FIGURE 13: FREQUENCY SPECTRA PLOT FOR THE CONFIGURATION WITHOUT VANES, $U_{m} /(\Omega b)=0.04, \Omega=9000 \mathrm{rpm}$.

Considering the vaned configuration results in Tab. 5, reducing rotor speed shifts these flow structures towards higher normalised frequencies and relative rotating speeds. Examination of the peaks showed that amplitudes were highest for the 6000rpm case which, as shown below, has slightly more ingestion than the two higher speed cases.

TABLE 4: FEATURES OF ROTATING FLOW MODES FOR THE VANELESS CONFIGURATION. $f / \Omega$ : USTEADY FLOW MODE FREQUENCY NORMALISED BY ROTOR DISC FREQUENCY. $\omega_{s} / \Omega$ : SPEED OF THE UNSTEADY FLOW MODES NORMALISED WITH THE DISC SPEED. $N$ : LOBE NUMBER OF FLOW MODE IN A FULL $360^{\circ}$ ANNULUS. $\Omega=9000$ RPM, $U_{m} / \Omega b=0.04$.

\begin{tabular}{cccc}
\hline Case & $\boldsymbol{f} / \boldsymbol{\Omega}$ & $\boldsymbol{\omega}_{\boldsymbol{s}} / \boldsymbol{\Omega}$ & $\boldsymbol{N}$ \\
\hline \multirow{2}{*}{$10^{\circ}$ sector } & 11.2 & 0.32 & 36 \\
$10^{\circ}$ sector with inner seal swirl & 22.7 & 0.31 & 72 \\
$v_{\theta, i}=0.5 \Omega r_{m, i}$ & 22.3 & 0.33 & 36 \\
$20^{\circ}$ sector & 11.8 & 0.32 & 72 \\
& 23.9 & 0.33 & 36 \\
\hline
\end{tabular}

TABLE 5: FEATURES OF ROTATING FLOW MODES FOR THE VANED CONFIGURATION. $f / \Omega$ : USTEADY FLOW MODE FREQUENCY NORMALISED BY ROTOR DISC FREQUENCY. $\omega_{s} / \Omega$ : SPEED OF THE UNSTEADY FLOW MODES NORMALISED WITH THE DISC SPEED. $N$ : LOBE NUMBER OF FLOW MODE IN A FULL $360^{\circ}$ ANNULUS.

\begin{tabular}{cccc}
\hline Rotor speed (rpm) & $\boldsymbol{f} / \boldsymbol{\Omega}$ & $\boldsymbol{\omega}_{\boldsymbol{s}} / \boldsymbol{\Omega}$ & $\boldsymbol{N}$ \\
\hline 6000 & 38.3 & 0.51 & 72 \\
7850 & 30.4 & 0.40 & 72 \\
9000 & 27.4 & 0.36 & 72 \\
\hline
\end{tabular}

The flow within the seal and the combined effects of rotation and the annulus pressure asymmetry (induced by the vanes) on ingestion are of particular interest. Figure 14 shows the propagation of the annulus circumferential pressure asymmetry into the chute seal for the three vaned test cases. These results are time averaged. The pressure coefficient is defined as the ratio of the relative static pressure to the rotor disc rim dynamic head $\left(C_{p, a}=\left|p-p_{\text {mean }}\right| /\left(0.5 \rho \Omega^{2} b^{2}\right)\right)$. The solutions from URANS and WMLES are plotted against the NGV pitch at the positions of probes P4 and P5 as given in Fig. 13. WMLES shows stronger pressure asymmetry than URANS. This is consistent with sealing effectiveness results presented later. It is further noted that although $C_{p, a}$ is more uniform at higher speeds, the dimensional pressure asymmetry increases. As expected the cavity pressure asymmetry is reduced towards the seal inner radius at probe $\mathrm{P} 4$.
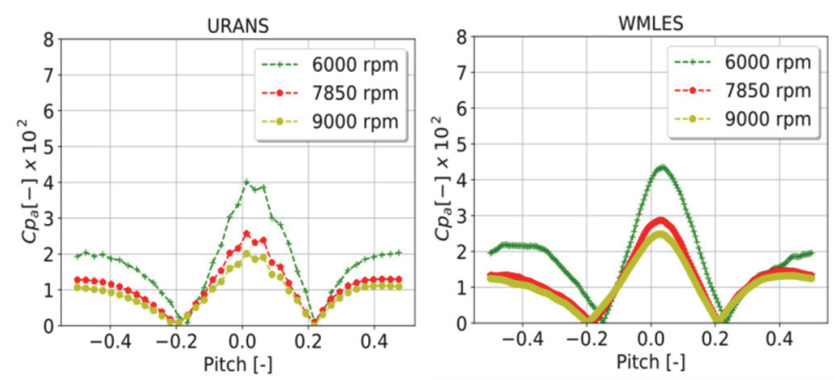

(a) PROBE LOCATION 5
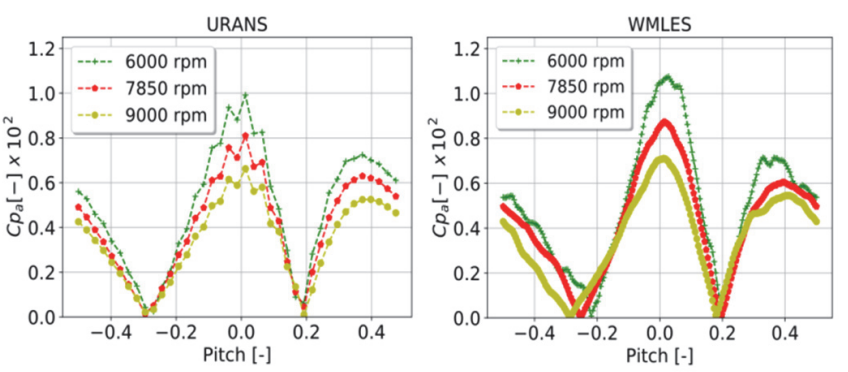

(b) PROBE LOCATION 4

FIGURE 14: TIME AVERAGED PRESSURE COEFFICIENT. COMPARISON BETWEEN URANS AND WMLES FOR THE VANED CONFIGURATION. PROBE LOCATIONS ARE GIVEN IN FIG. 13.

Figure 15 shows time- and circumferentially-averaged normalised tangential velocity profiles in the chute seal for the 
configuration with vanes. Results are given at two axial sampling lines at the radii of probes 4 and 5 as shown in Fig. 13. Qualitative agreement between URANS and WMLES can be observed. However, WMLES predicts more entrainment of the highly swirling main annulus flow into the chute seal compared to URANS.

\subsection{Sealing Effectiveness}

As discussed above, convergence of the sealing effectiveness can take longer than that of the pressure. For each case, the evolution of the sealing effectiveness was monitored. Convergence to statistically steady state took $\sim 10$ rotor revolutions and the convergence of statistics $(\langle\varepsilon\rangle)$ was achieved with $\sim 5$ rotor revolutions, as illustrated in Fig. 16.

Sealing effectiveness distributions on the stator disc are shown in Figs. 17 and 18. Here, the sealing effectiveness is averaged in the circumferential direction and in time over the last rotor revolution simulated. Values were obtained at discrete points on the stator as shown in the figures. The experimental values presented were obtained from concentration measurements as described by Bru Revert et al. [23]. Figure 17 shows the results for the configuration without vanes. In this case ingestion is driven by disc pumping. The WMLES predicts significant ingestion in fair agreement with the measurements, while the URANS results show the cavity to be effectively sealed. Notably, the addition of inlet swirl clearly improves ingestion prediction towards experiments.
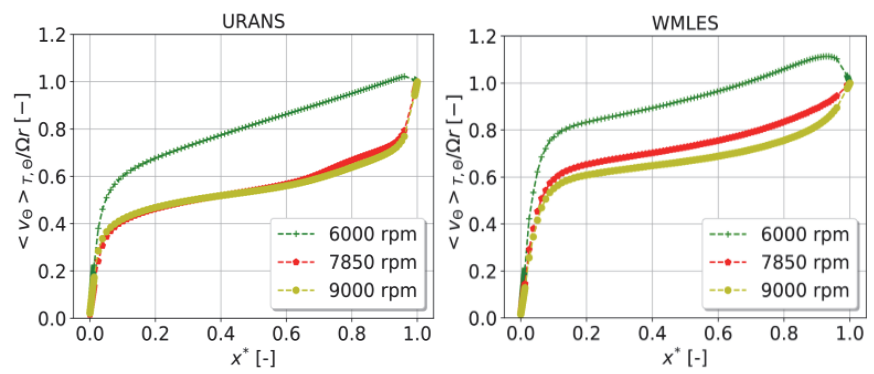

(a) AXIAL PROFILES AT THE RADIUS OF PROBE 5
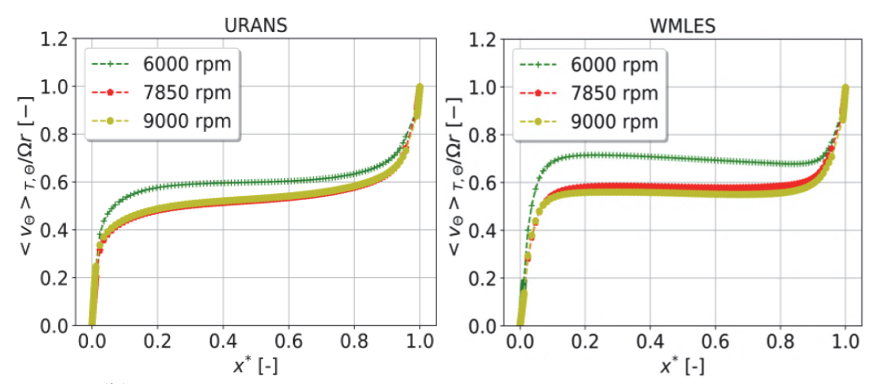

(b) AXIAL PROFILES AT THE RADIUS OF PROBE 4

FIGURE 15: TIME- AND CIRCUMFERENTIALLY-AVERAGED NORMALISED TAGENTIAL VELOCITY PROFILES. COMPARISON BETWEEN URANS AND WMLES. VANED CONFIGURATION. PROBE LOCATIONS ARE GIVEN IN FIG. 13.
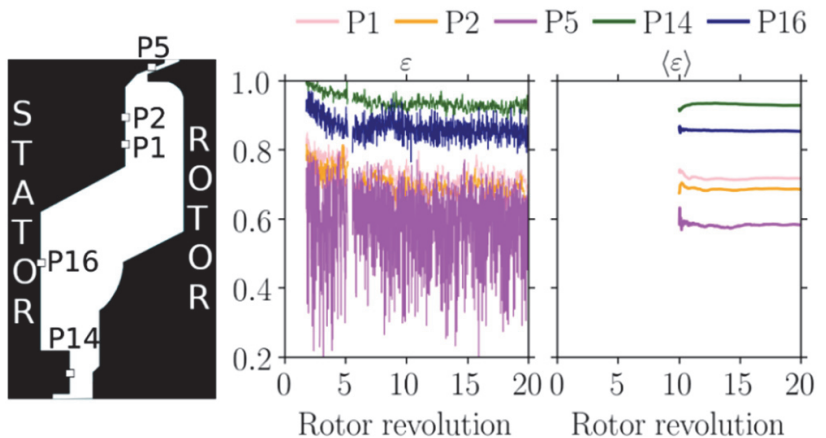

FIGURE 16: SEALING EFFECTIVENESS STATISTICAL CONVERGENCE FOR WMLES AT 9000 RPM, CONFIGURATION WITHOUT VANES

Figure 18 shows results for the configuration with vanes for the three rotor speeds considered. Again, the WMLES predicts significant ingestion for cases where URANS shows effective sealing. However, at 6000rpm, where the URANS results do show ingestion, the two models show less difference in sealing effectiveness, especially in the inner part of the cavity. Towards the outer part of the cavity the WMLES results are relatively close to the measurements. The measurements clearly show lower effectiveness in the inner part of the cavity. The reasons for this discrepancy are not fully understood. They might include modelling assumptions such as the $10^{\circ}$ periodic sector, approximated cavity inlet flow conditions or failure to capture some effects of the cavity shape and/or experimental effects such as larger scale (but small amplitude) deviations from the axisymmetric inlet conditions and eccentricity. With an earlier build of the rig it was noted that the effect of boltheads in the inner cavity could be seen in pressure measurements in the rim seal. These bolt-heads were not present in the experiments shown here, but the result showed sensitivity of the rim seal flow to relatively small changes in the rig geometry. As shown in Fig. 18(c), introducing inlet swirl for the 9000rpm case did not show any effect on ingestion, in contrast to the results for the vaneless case in Fig. 17.

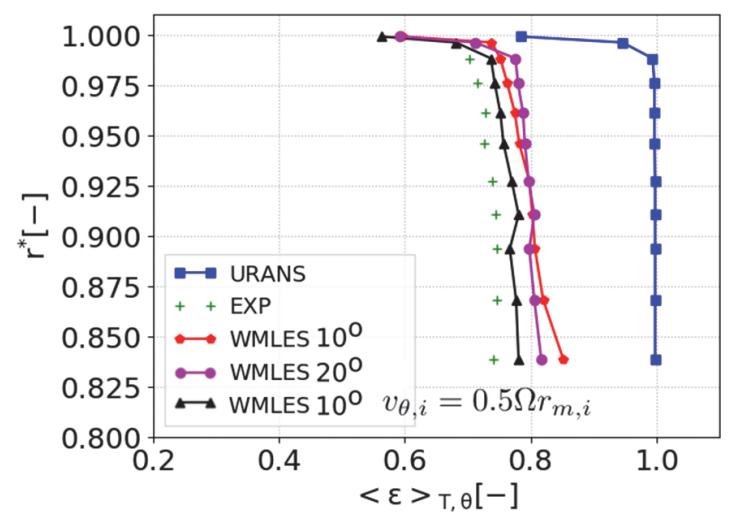

FIGURE 17: TIME- AND CIRCUMFERENTIALLY-AVERAGED SEALING EFFECTIVENESS. VANELESS CONFIGURATION, 9000RPM. 


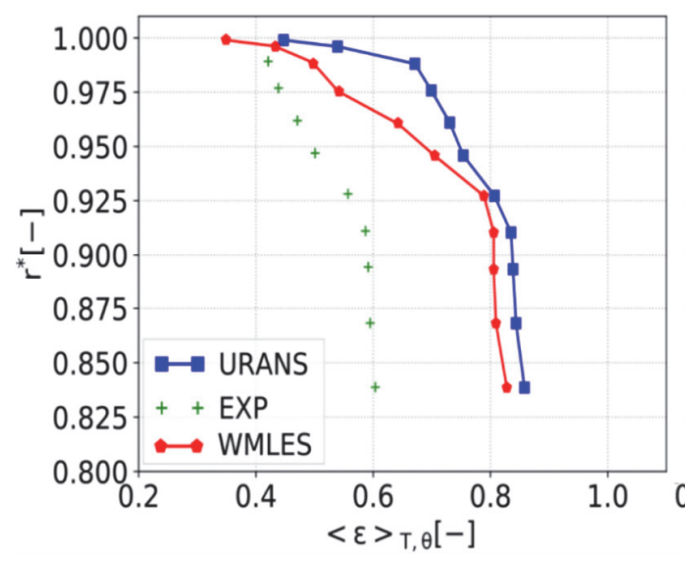

(a) $6000 \mathrm{rpm}$

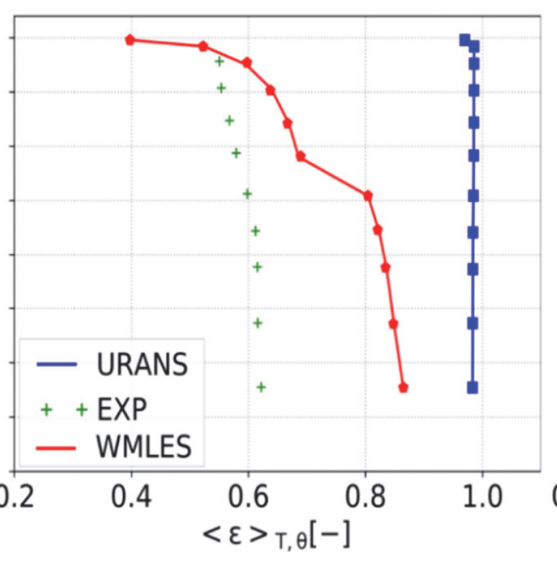

(b) $7850 \mathrm{rpm}$

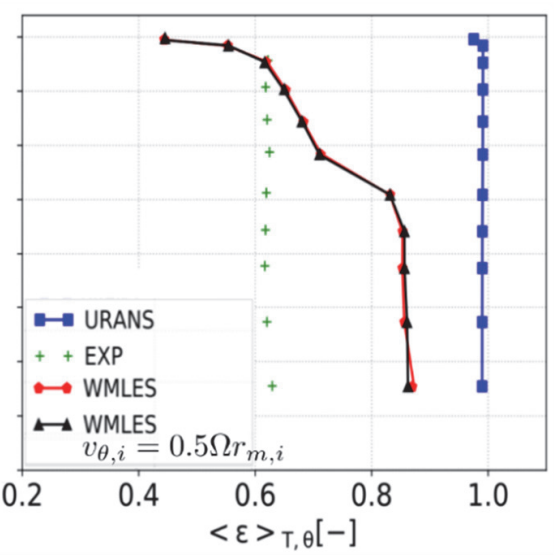

(c) $9000 \mathrm{rpm}$

FIGURE 18: TIME- AND CIRCUMFERENTIALLY-AVERAGED SEALING EFFECTIVENESS OVER STATOR NON-DIMENSIONAL RADIUS FOR THE CONFIGURATION WITH VANES.

\section{CONCLUSIONS}

A CFD code previously adapted and demonstrated for LES in rotating disc cavity flows has been extended to allow calculation of a passive scalar concentration. The WMLES has been shown to give reasonable results for benchmark test cases and has been applied to study ingestion through a chute turbine rim seal with and without nozzle guide vanes in the main annulus. The principal conclusions are summarised below.

- WMLES is effective in improving on URANS modelling for turbine rim sealing, and offers a computationallyaffordable alternative to wall resolved LES.

- For all cases considered here WMLES predicted greater ingestion than URANS. This includes rotationally-driven ingestion and ingestion with an annulus pressure asymmetry induced by stationary vanes.

- Both WMLES and URANS solutions show the vaneinduced pressure asymmetry propagates into the chute seal but decays rapidly towards the seal inner radius. The dimensional pressure asymmetry in the seal increases as the rotational speed increases, but relative to the disc speed dynamic head the strength of the asymmetry reduces with rotor speed.

- In all cases considered, WMLES shows rotating inertial waves in the chute seal. Secondary flow structures are not sensitive to a doubling of sector size for the vaneless configuration.

- Good agreement of WMLES with measured sealing effectiveness is shown for the rationally-driven ingestion without vanes.

- For the cases considered with vanes WMLES overpredicts the measured sealing effectiveness, particularly in the inner part of the cavity. This may be associated with the limited sector size, inlet condition assumptions or other experimental effects not modelled such as small eccentricities, etc.

\section{ACKNOLEDGMENT}

Funding for this research from EPSRC, Innovate UK and Rolls-Royce plc is gratefully acknowledged. Support from colleagues from the Universities of Surrey and Oxford and Rolls-Royce plc is also much appreciated. In particular, we would like to thank Sebastiaan Bottenheim, Matthew Miller and Peter Smout of Rolls-Royce.

\section{REFERENCES}

1. O'Mahoney, T. S. D., Hills, N. J., Chew, J. W., and Scanlon, T., 2011. "Large-eddy simulation of rim seal ingestion". Proceedings of the Institution of Mechanical Engineers, Part C: Journal of Mechanical Engineering Science, 225(12), pp. 2881-2891.

2. Gao, F., Chew, J. W., and Marxen, O., 2020. "Inertial waves in turbine rim seal flows". Physical Review Fluids, 5(2), p. 024802.

3. Chew, J. W., Gao, F., and Palermo, D. M., 2019. "Flow mechanisms in axial turbine rim sealing". Proceedings of the Institution of Mechanical Engineers, Part C: Journal of Mechanical Engineering Science, 233(23-24), pp. 7637-7657.

4. Amirante, D. and Hills, N. J., 2015. "Large-eddy simulations of wall bounded turbulent flows using unstructured linear reconstructions techniques". Journal of Turbomachinery, 137(5), p. 051006.

5. Gao, F., Chew, J. W., Beard, P. F., Amirante, D., and Hills, N.J., 2018. "Large-eddy simulation of unsteady turbine rim sealing flows", International Journal of Heat and Fluid Flow, 70, pp. 160-170.

6. Beard, P. F., Gao, F, Chew, J. W., and Chana, K. S., 2016. "Unsteady flow phenomena in turbine rim seals". Journal of Engineering for Gas Turbines and Power, 139(3), p. 032501.

7. Gao, F., Poujol, N., Chew, J. W., and Beard, P. F., 2018. "Advanced numerical simulation of turbine rim seal 
flows and consideration for RANS turbulence modelling”. In Proceedings of ASME Turbo Expo 2018: Turbine Technical Conference and Exposition. Paper No. GT2018-75116.

8. Almendral-Fernandez, G., Amirante, D., and Hills, N. J., 2018. "Use of zonal hybrid URANS/LES methodology for prediction of rim seal ingestion into a low pressure turbine cavity". In Proceedings of AIAA 2018 Joint Propulsion Conference. Paper No. AIAA2018-4917.

9. Spalart, P., and Allmaras, S., 1994. "A one-equation turbulence model for aerodynamic flows". La Recherche Aérospatiale, 1, pp. 5-21.

10. Horwood, J. T. M., Hualca, F. P., Scobie, J. A., Wilson, M., Sangan, C. M., and Lock, G. D., 2018. "Experimental and computational investigation of flow instabilities in turbine rim seals". Journal of Engineering for Gas Turbines and Power, 141(1), p. 011028.

11. Horwood, J. T. M., Hualca, F. P., Scobie, J. A., Wilson, M., Sangan, C. M., Lock, G. D., Dahlqvist, J., and Fridh, J., 2020. "Flow instabilities in gas turbine chute seals". Journal of Engineering for Gas Turbines and Power, 142(2), p. 021019.

12. Pogorelov, A., Meinke, M., and Schröder, W., 2018. "Large-eddy simulation of the unsteady full 3D rim seal flow in a one-stage axial-flow turbine". Flow, Turbulence and Combustion, 102(1), pp. 189-220.

13. Bridel-Bertomeu, T., Gicquel, L. Y., and Staffelbach, G., 2016. "Wall modelled LES and its impact on rotorstator/cavity unsteady features". In Proceedings of ASME Turbo Expo 2016: Turbomachinery Technical Conference and Exposition. Paper No. GT2016-57244.

14. Kusbeci, M. E. and Chew, J. W., 2018 "Assessment of wall-modelled LES for pre-swirl cooling systems". In Proceedings of ASME Turbo Expo 2018: Turbomachinery Technical Conference and Exposition. Paper No. GT2018-75112.

15. Da Soghe, R., Bianchini, C., and D'Errico, J., 2017. "Numerical characterization of flow and heat transfer in pre-swirl systems". In Proceedings of ASME Turbo Expo 2017: Turbomachinery Technical Conference and Exposition, Paper No. GT2017-64503.

16. Roe, P. L., 1981. "Approximate Riemann solvers, parameter vectors, and difference schemes", Journal of Computational Physics, 43(2), pp. 357-372.

17. Moinier, P., 1999. "Algorithm developments for an unstructured viscous flow solver", Ph.D. thesis. University of Oxford.

18. Spalding, D. B., 1961, "A single formula for the law of the wall". Journal of Applied Mechanics, 28(3), pp. 455458.

19. Bose, S. T. and Park G. I., 2018. "Wall-modeled largeeddy simulation for complex turbulent flows", Annual. Review of Fluid Mechanics, 50, pp. 536-561.

20. Boudet, J., 2005. "Numerical simulation of rim sealing in axial turbines". Internal Report TFS-UTC/2005/05.
21. Séverac, É., Poncet, S. Serre, É. and Chauve M.-P., 2007. "Large eddy simulation and measurements of turbulent enclosed rotor-stator flows", Physics of Fluids, 19, p. 085113.

22. Daily, J. W., and Nece, R. E., 1960. "Chamber dimension effects on induced flow and frictional resistance of enclosed rotating disks", Journal of Basic Engineering, 82(1), pp. 217-230.

23. Bru Revert, A., Beard, P. F., Chew, J. W., and Bottenheim, S., 2020, "Performance of a turbine rim seal subject to rotationally-driven and pressure-driven ingestion", In Proceedings of ASME Turbo Expo 2020: Turbomachinery Technical Conference and Exposition. Paper No. GT2020-14773.

24. Palermo, D. M., Gao, F., Chew J. W., and Beard P. F., 2019. "Effect of annulus flow conditions on turbine rim seal ingestion", In Proceedings of ASME Turbo Expo 2019: Turbomachinery Technical Conference and Exposition. Paper No. GT2019-90489.

25. Ansys Inc., ANSYS ICEM, 2017.

26. Onori, M., Amirante D., Hills, N. J., and Chew J. W., 2019. "Heat transfer prediction from large eddy simulation of a rotating cavity with radial inflow", Journal of Engineering for Gas Turbines and Power. 141(12), p. 121002.

27. Poinsot, T. J., Lele, S. K., 1992. "Boundary conditions for direct simulations for compressible viscous flows". Journal of Computational Physics, 101(1), pp. 104-129. 